\title{
Consumer attitudes, knowledge, and consumption of organic yogurt
}

\author{
Ellen J. Van Loo, ${ }^{1}$ My Nguyen Hoang Diem, Zuzanna Pieniak, and Wim Verbeke \\ Department of Agricultural Economics, Ghent University, 9000 Gent, Belgium
}

\begin{abstract}
The segment of organic products occupies an increasingly important place in dairy assortments. The European Union (EU) introduced a new EU organic logo in 2010 with the aim of harmonizing its organic sector and boosting consumer trust in organic food. This study focuses on organic yogurt and investigates consumer awareness and knowledge of the new EU logo. Consumers evaluate organic yogurt as superior compared with conventional yogurt on healthiness, environmental friendliness, quality, and safety. More frequent buyers of organic yogurt have a stronger belief that organic yogurt is superior. The willingness-to-pay for organic yogurt ranged from a premium of $15 \%$ for nonbuyers to $40 \%$ for habitual buyers, indicating the market potential for this product. A structural equations model reveals the positive association between knowledge, attitudes, and the frequency of purchasing and consuming organic yogurt. Nevertheless, consumer awareness of the EU organic logo remains rather low, which suggests a need for more effective information campaigns and marketing actions.
\end{abstract}

Key words: organic yogurt, organic food, structural equation modeling, consumer behavior

\section{INTRODUCTION}

Within the dairy industry, organic dairy is gaining importance in the European Union (EU). Dairy products, together with fresh fruit and vegetables, are the most popular organic food categories (Soil Association, 2012). Production of organic milk is the largest in Germany (595 million kg of organic milk in 2010), Denmark (440 million $\mathrm{kg}$ ), the United Kingdom (470 million $\mathrm{kg}$ ), Austria (425 million $\mathrm{kg}$ ), France (266 million kg), Sweden (180 million kg), Switzerland (205 million kg), and the Netherlands (140 million kg; BioForum, 2011). In some EU countries, such as Austria and Denmark, organic milk production reached a remarkable 14 and $9.8 \%$ of the total milk production in 2010 (BioForum,

Received October 12, 2012.

Accepted December 31, 2012.

${ }^{1}$ Corresponding author: ellen.vanloo@UGent.be
2011), respectively. In Belgium, annual organic milk product was estimated at 32 million $\mathrm{kg}$ in $2010,1.1 \%$ of the total milk production; this number is expected to continue to expand. In most European countries (with the exception of the United Kingdom), the supply of organic milk is unable to keep up with the growing demand, resulting in a shortage of organic milk. As a result, several countries are importing organic milk from elsewhere. For example, France, the Netherlands, and Belgium are importing organic milk from the United Kingdom (BioForum, 2011). An estimated 23 million L of raw organic milk was imported in Belgium in 2010 (BioForum, 2011).

The EU organic food sales were estimated at $€ 19.6$ billion in 2010 (IFOAM/FiBL, 2012); in Belgium, the organic food sector was valued at $€ 435$ million in 2011 (VLAM, 2012). Belgian consumers' spending on organic dairy products was $€ 46$ million in 2011 (VLAM, 2012), which is an 84\% increase compared with 2007. In Belgium, as in other EU countries (Soil Association, 2012), dairy products rank second in terms of importance within the organic food basket, preceded only by fresh fruit and vegetables (VLAM, 2012). In 2011, approximately $60 \%$ of Belgian consumers chose to occasionally purchase organic vegetables, followed by organic fruit, with $39 \%$, and organic dairy, which was bought occasionally by approximately one-third $(32 \%)$ of Belgian consumers (VLAM, 2012).

The expanding organic food industry is the result of the growing demand for organic food. One of the reasons for growing demand is the increasing number of consumer concerns about the conventional food production. The key driver for organic food consumption is most likely the belief that organic food is healthier and safer compared with its conventional counterparts (Magnusson et al., 2003; Padel and Foster, 2005; Yiridoe et al., 2005; Hughner et al., 2007; Gracia and Magistris, 2008; Van Loo et al., 2010; Aertsens et al., 2011). Conversely, some factors prevent consumers from purchasing organic food; key deterrents are high premiums for organic food in combination with low availability (Yiridoe et al., 2005; Hughner et al., 2007; Van Loo et al., 2010). According to Mondelaers et al. (2009), consumers frequently buying organic food are less affected by the high prices compared with light us- 
ers. Other barriers include the unfamiliarity of organic food logos, skepticism about organic certification logos, and disbelief that organic food is better (Van Loo et al., 2012). For an organic label to be successful it is important that the logo be well-known and trusted by the consumers (Janssen and Hamm, 2012a).

Numerous different organic food certifications exist across Europe, from both governmental and private organizations. With the aim of harmonizing the EU organic food sector and increasing consumer trust in the organic certification, the EU introduced a new organic food logo in 2010. This new logo became mandatory for use on all organic food products in the EU in 2012 after a 2-yr transition period (EG 834/2007, EG 889/2008, and EG 271/2010; the EU logo used before 2012 will further be referred to as the "former organic EU logo"). With the introduction of the mandatory organic food logo, the EU aims to establish a harmonized organic certification system and hopes to improve the recognition of organic food by consumers with one logo (EG 271/2010). The European Commission reported that two-thirds of Europeans check foods for quality labels; however, recognition of individual quality labels is fairly low. Only $24 \%$ of the Europeans are aware of the new EU organic food logo (European Commission, 2012). Both national organic logos (such as BioSiegel) and organic logos certified by private organizations (for example Biogarantie, BioSuisse, or Soil Association) coexist with the EU organic logo. On the Belgian organic food market, 2 organic food logos are present: (1) the new EU organic food logo, and (2) the Biogarantie logo, which is the logo of a private Belgian organization. The EU organic logo is mandatorily present on all organic foods in Europe, whereas the Biogarantie logo is voluntary. The Biogarantie logo has some additional ethical requirements based on 4 principles: health, ecology, fairness, and care (BioForum, 2012). Many organic food producers and retailers still use the voluntary governmental logos or private organic certification along with the mandatory EU organic food logo, most likely to prevent losing consumers familiar with the voluntary logos only (Janssen and Hamm, 2012a). However, to be certified by a private organic organization, such as Biogarantie, additional conditions need to be fulfilled besides those for EU organic certification.

Consumers are willing to pay a premium price for organic food; studies reported willingness-to-pay (WTP) values ranging from 5 to $250 \%$ (Turco, 2002; Batte et al., 2007; Van Loo et al., 2011) depending on the country, product, and socio-demographic factors. The reported WTP values also differ depending on the type of organic food logo. Janssen and Hamm (2012a) reported different WTP values for the former organic
EU logo, governmental organic logos, and organic logos from private organizations, such as farmers' and organic sector associations. Consumers from different countries have different preferences for the type of organic logo. For example, in Italy, the former organic EU logo was preferred over the governmental or private organic logos; whereas, in Denmark and Germany the opposite was observed (Janssen and Hamm, 2012a). The average premium for organic food in Belgium was $30 \%$ in 2011 (VLAM, 2012). The premium for organic milk in Belgium compared with conventional milk was $64 \%$ in 2010 and decreased to $55 \%$ in 2011; for yogurt, the average premium for organic increased from $29 \%$ in 2010 to $37 \%$ in 2011 (VLAM, 2012).

Research on consumer preferences and attitudes toward organic dairy is limited. Lusk (2011) reported that consumer demand for organic milk is significantly influenced by food values; the demand for organic milk is higher for consumers who are more concerned about the environment and lower for those who are more conscious about the price. Although organic dairy is the third largest organic food sector (following organic fruit and organic vegetables), little research exists focusing on consumer perception and attitudes toward organic dairy and organic yogurt, specifically.

In this study, we address the need to broaden knowledge on consumer attitudes toward organic dairy. Our study gives insight on the consumer recognition of the new EU organic logo vis-à-vis the most prevalent organic food logo in Belgium certified by a private organization. This gives information about the success of the mandatory EU organic logo, which aims to increase the consumer recognition and knowledge. Only the European Commission Eurobarometer evaluated the new EU organic logo after the 2-yr transition period, along with other consumer attitudes of food quality and food security (European Commission, 2012). However, that study only investigated the awareness of the logo and did not explore attitudes and purchase frequencies. To our knowledge no study has evaluated the new EU organic logo in combination with attitudes and consumption behavior of organic foods. In addition, limited research has focused on organic dairy products and consumer attitudes and knowledge toward these products; this study focuses on both of these issues.

Finally, this study examines whether knowledge about organic food and consumer attitudes are associated with frequency of organic yogurt consumption. Both knowledge about organic food and attitudes toward organic food are important determinants for organic food consumption (de Magistris and Gracia, 2008; Pieniak et al., 2010). Different consumer segments exist based on their attitude toward organic food. Several other 
Table 1. Knowledge statements on the meaning of the EU organic logo

\begin{tabular}{|c|c|c|c|}
\hline The logo indicates that & $\begin{array}{l}\text { Correct } \\
\text { answer }\end{array}$ & $\begin{array}{c}\% \text { Correct } \\
\text { answer }\end{array}$ & $\begin{array}{c}\text { \% Wrong } \\
\text { answer }\end{array}$ \\
\hline At least $95 \%$ of the ingredients are organic & True & 52 & 48 \\
\hline At least $70 \%$ of the ingredients are organic & False & 63 & 37 \\
\hline It can be used for products derived from fishing and hunting wildlife activities & False & 70 & 30 \\
\hline
\end{tabular}

studies have indicated the importance of recognizing and identifying consumer segments based on their product usage (Hoek et al., 2011; Van Loo et al., 2011; Pino et al., 2012) to develop communication strategies tailored toward the different consumer segments. Based on the frequency of consuming organic yogurt, different consumer groups are defined.

\section{MATERIALS AND METHODS}

Quantitative descriptive data were collected through a cross-sectional consumer survey in the northern, Dutch speaking part of Belgium (Flanders) in March 2012 targeting the main individual responsible for food purchasing. Total sample size was 774 respondents; participants were selected from the proprietary consumer panel, managed by the market research company responsible for data collection. Such panels consist of individuals who have been recruited through off-line recruitment methods (e.g., random walk-up or street contact procedures) and who agreed to take part in future surveys. All contact and questionnaire administration procedures were electronic and anonymity was guaranteed.

The questionnaire consisted of different parts related to awareness and knowledge of organic food labels, attitudes toward conventional and organic yogurt, purchase behavior regarding organic yogurt, including WTP, involvement, and socio-demographics.

\section{Awareness and Knowledge of Organic Food Logos}

To quantify awareness of the EU organic food logo, recognition and objective knowledge were measured. Respondents were asked if they recognized the EU organic logo shown (yes/no) as well as the Biogarantie logo (yes/no). Next, their objective or factual knowledge of the meaning of the EU organic logo was measured by asking respondents whether 4 statements were true or false, presented in Table 1. Following a similar approach as Pieniak et al. (2010), no "don't know" answer was included to force the respondents to answer the question. The objective knowledge measure was calculated as the total number of correct responses to the 4 statements, thus ranging from 0 to 4 .

\section{Purchase Behavior of Organic Yogurt}

Purchase Frequency of Organic Yogurt. Respondents were asked "Out of 10 times that you buy yogurt, how often do you choose yogurt with an organic logo?" An 11-point scale ranging from never $=0$ to always $=10$ was used to identify the frequency of organic yogurt purchases. Throughout the presentation of the results, a comparison between consumers who never, occasionally, and regularly purchase organic yogurt was noted. Those answering 0 or 1 are considered "nonorganic yogurt buyers," from 2 to 6 were "occasional buyers," and 7 to 10 were "habitual buyers."

As indicated by Pino et al. (2012) and Van Loo et al. (2010), who also applied a classification of consumers according to their buying frequency, this distinction is important for the use of targeted, tailored communication strategies by food marketers and policy makers to different consumer groups.

Purchase Intention for Organic Yogurt. Respondents indicated with 3 statements, how likely or unlikely it is that they expect, plan, and desire to eat organic yogurt in the next 7 d (Pérez-Cueto et al., 2011). A 7-point interval scale ranging from "very unlikely" to "very likely" was used. The purchase intention was calculated as the average of the 3 answers (Cronbach's $\alpha=0.977)$.

$\boldsymbol{W T P}$. The average price of $500 \mathrm{~g}$ of conventional yogurt was set at $€ 1.50$ (reference price). Respondents were asked how much they are willing to pay extra for yogurt $(500 \mathrm{~g})$ with an organic logo. Possible answers ranged from $€ 0$ to $€ 1.50$ euro. A no-buying option was also included ("I would buy regular yogurt based on the price of organic yogurt.") to make the design more comparable to real shopping experiences where consumers can also decide not to purchase organic yogurt (Van Loo et al., 2011).

\section{Attitudes and Involvement Toward (Organic) Yogurt}

Importance of Yogurt Attributes. The importance of yogurt attributes was scored on a 7-point Likert scale ranging from "totally disagree" to "totally agree." Ten attributes (such as taste, quality, and availability) were included based on previous studies (Grankvist and Biel, 2001; Vanhonacker and Verbeke, 2009). 
Beliefs About Organic Yogurt Compared with Conventional Yogurt. Adapted from Hoogland et al. (2007) and Vanhonacker and Verbeke (2009), participants compared 9 aspects of organic yogurt with conventional yogurt, such as taste, healthiness, and environmental friendliness. Perceived differences among organic and conventional yogurt were identified with the question, "Organic yogurt scores (worse/better) than conventional yogurt in terms of..." Responses were scored on a 7 -point scale with $1=$ much worse, $2=$ worse, $3=$ somewhat worse, $4=$ same, $5=$ somewhat better, $6=$ better, $7=$ much better.

General Attitudes Toward Organic Yogurt. General attitudes toward organic yogurt were measured using 7-point semantic differential scales. Respondents were presented with the statement, "Please indicate which word best describes your feeling toward organic yogurt compared to conventional yogurt." The bipolar adjectives were bad/good, unpleasant/pleasant, and negative/positive; a commonly used scale for assessing general attitudes (Stayman and Batra, 1991; Honkanen et al., 2006; Olsen et al., 2007; Pieniak et al., 2010; Pérez-Cueto et al., 2011). The construct "general attitude towards organic yogurt" is the average across the 3 items (Cronbach's $\alpha=0.963$ ).

Involvement. Involvement relates to the importance of the product and the extent to which the right product choice is important to the consumer (Zaichkowsky, 1985). The degree of involvement will affect the time and effort devoted to making the purchasing decision. The involvement in organic food was measured according to the procedure of Bell and Marshall (2003) and Pieniak et al. (2008) using the 4 items: "Organic food means a lot to me," "I care a lot about organic food," "Organic food is very important to me," and "I appreciate organic food very much." Involvement with organic food was calculated as the average score across the 4 items (Cronbach's $\alpha=0.966$ ).

\section{Data Analysis}

The survey data were analyzed in SPSS 19 (SPSS Inc., Chicago, IL). Constructs were formed as indicated after testing the reliability (Cronbach's $\alpha$ ). To test for independence in cross-tabular data, chi-squared tests were performed. A $t$-test was applied to compare 2 means and ANOVA was performed to compare more than 2 means. Scheffé or Dunnett T3 post hoc were performed in cases where equal variances could or could not be assumed. In all statistical tests a significance level of 0.05 was used to identify significant differences.

\section{Structural Equation Modeling}

Structural equation modeling was performed to analyze whether knowledge about the organic food logo and consumer attitudes are associated with frequency of organic yogurt consumption. Structural equations model parameters were estimated and the general fit of the model was assessed using the robust maximum likelihood procedure in LISREL 8.72. To evaluate the fit of the model, the $\chi^{2}$-value, together with degrees of freedom, are reported, as well as 3 other indices: the root mean square error of approximation, the validity of fit index, and the comparative fit index. Values below 0.08 for root mean square error of approximation (Browne and Cudeck, 1993) and above 0.90 for validity of fit index and comparative fit index (Bollen, 1989) indicate an acceptable fit of the model.

\section{RESULTS AND DISCUSSION}

\section{Characteristics of the Sample}

A total of 774 respondents completed the survey (Table 2). The demographic analysis reveals a sex distribution of $62 \%$ female and $38 \%$ male, which corresponds with females being the main people responsible for food purchasing in most households. Each age category is represented, as well as different compositions of households (number of adults and children). The sample is slightly biased toward more highly educated respondents $(>70 \%$ with education beyond the age of $18 \mathrm{yr}$ ), which may be attributed to the use of an electronic survey method. Most of the respondents worked full- or part-time. Most participants had moderate (35\%) or moderate to well-off $(53 \%)$ financial status. This subjective assessment of the household's financial situation is a proxy of socio-economic class.

\section{Frequency of Buying: Types of Consumers}

Approximately $57 \%$ of the respondents were identified as nonbuyers, whereas $43 \%$ of the respondents purchase organic yogurt (26\% occasional and 17\% habitual buyers). Similarly, based on Gesellschaft für Konsumforschung (GfK) Panel data, VLAM (2012) reported that $33 \%$ of Belgian consumers purchased organic dairy products in 2011. Our results show slightly higher percentages of buyers, which could be an outcome of the large percentage of women in our sample.

\section{Profile of Organic Yogurt Consumers}

Little demographic differences were prevalent among the 3 types of buyers (Table 2). The frequency of buy- 
Table 2. Organic yogurt consumption among different demographic groups

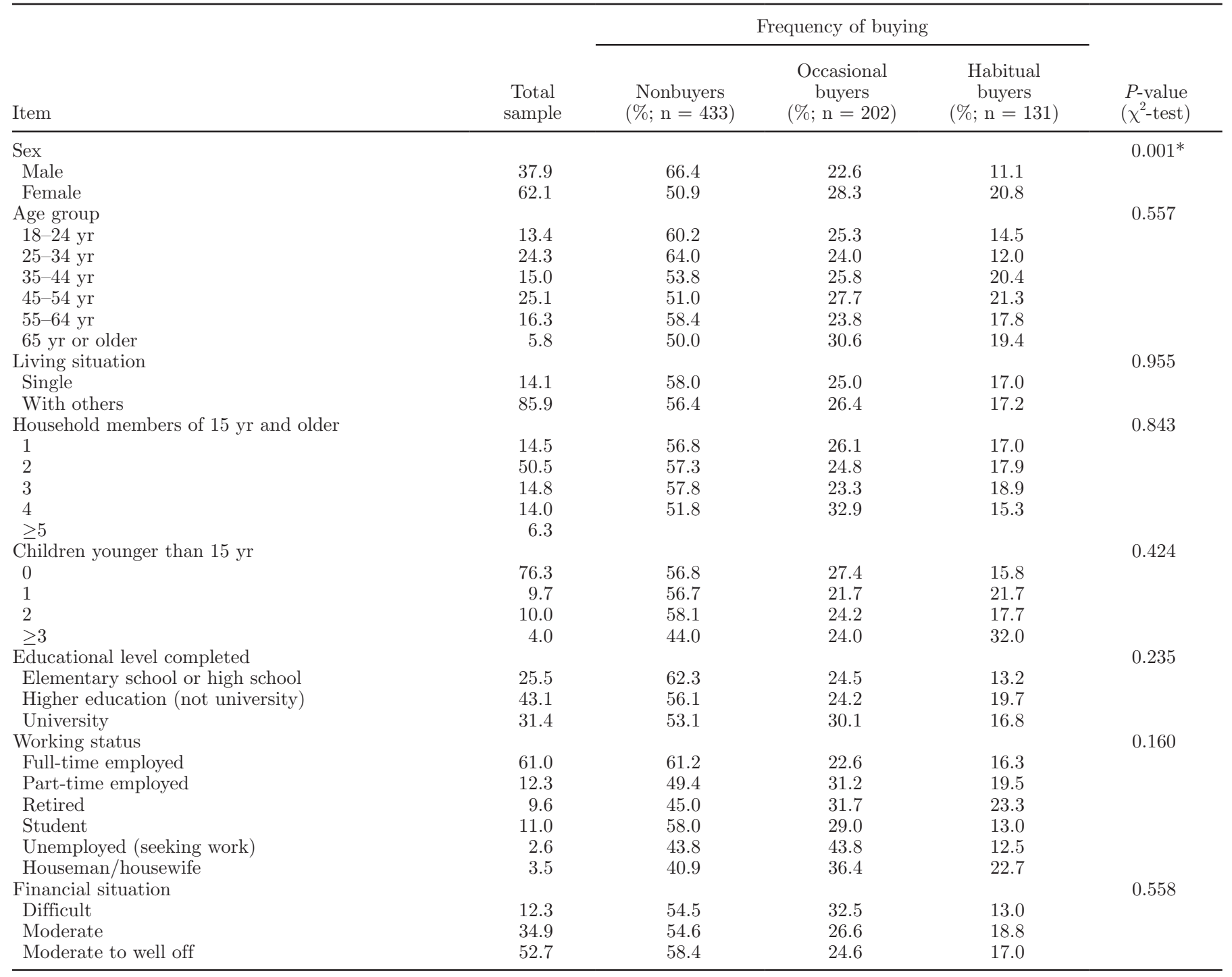

ing differs significantly among men and women $(P<$ 0.001 ), with women being more likely to purchase organic yogurt. This might be due to women being more concerned about food safety and health (Tsakiridou et al., 2008), which have been shown to be important motives for purchasing organic food (Hoefkens et al., 2009). The other demographics are not significantly different among the 3 consumer groups, including age $(P=0.56)$, number of adults $(P=0.84)$, children in household $(P=0.42)$, education $(P=0.24)$, working status $(P=0.16)$, and self-reported financial situation $(P=0.56)$. Some inconsistency exists in the socio-demographic profile of organic consumers across different studies and a clear profile remains elusive (Pearson et al., 2011; Van Loo et al., 2012). Organic food buyers exist across all demographic segments, although some small trends have been reported: organic consumers are more likely to be women, high-income earners, younger, and have young children.

Our study is consistent with most studies reporting organic consumers to be typically female (Yiridoe et al., 2005; Hughner et al., 2007; Bellows et al., 2008; Zander and Hamm, 2010; Pearson et al., 2011). Some studies report that organic consumers are older (Hughner et al., 2007; Bellows et al., 2008; Van Loo et al., 2010), whereas others report that they are likely to be younger (Magnusson et al., 2001; Krystallis et al., 2006; Mintel, 2011). In our study, no relationship between age and organic food purchase behavior was noted, similar to O'Donovan and McCarthy (2002). Earlier studies also found that income does not have an influence on organic food purchases (Van Loo et al., 2010), whereas other studies report high income families to be more likely to purchase organic foods (Gracia and Magistris, 
2008; Mintel, 2011; Pearson et al., 2011). Children in the household may increase the likelihood of purchasing organic food (Hughner et al., 2007). However, Mintel (2011) reported that households without children, with one child, and with more than one child have equal consumption of organic yogurt and yogurt drinks (45\%), which is comparable to our results.

\section{Consumers' Recognition and Objective Knowledge of Organic Food Logos}

More than two-thirds of the participants (69\%) did not recognize the new EU organic food logo (Table 3). This is consistent with the results of the Eurobarometer study, where only $24 \%$ of EU respondents indicated recognition of the new EU organic food logo. However, awareness of the EU organic logo among EU member states varied, and for Belgian consumers the awareness was even lower (20\%; European Commission, 2012). A first requirement for a successful logo is that consumers recognize it. Our findings together with those from the European Commission suggest some major challenges for the EU organic food logo. As stated by Janssen and Hamm (2012a), logo awareness is a first prerequisite; however, in addition to the logo recognition, a successful logo also requires trust and credibility. Several studies indicated the uncertainty and lack of trust toward the organic food logo to be barriers for organic food purchases (Padel and Foster, 2005; Hughner et al., 2007; Aertsens et al., 2009; Van Loo et al., 2010).

The Biogarantie logo, a logo certified by a Belgian private organization, has much higher recognition, with more than half of the respondents (54\%) reporting recognition of this logo. This logo was introduced in 1988 and has not changed since then. Janssen and Hamm (2012b) studied consumers' perception of the new EU organic food logo in 2010. The results revealed that some consumers would still orient themselves by using the existing logos instead of the new EU organic logo. Even in 2012, after being exposed to this new logo for 2 years, our study has similar findings, with higher recognition of the private organic certification logo compared with the EU logo. The consumers' familiarity with the EU logo is likely related to the visibility of the EU organic logo in the marketplace (Janssen and Hamm, 2012b). The Biogarantie logo has been present on most organic food sales in Belgium since 1988, whereas use of the former organic EU logo was limited in previous years when the EU logo was not mandatory yet; this can explain these large differences in logo recognition between the 2 logos. Consumers currently not purchasing organic yogurt report the lowest recognition of both the EU organic and the Belgian organic food logo, followed by the occasional buyers and habitual buyers $(P$ $<0.001$; Table 3).

Objective knowledge of the meaning of the EU organic food logo was relatively low. Only $23 \%$ of study participants provided a correct answer to the 4 trueor-false statements (Table 3). Habitual buyers have a significantly greater knowledge about the EU organic food logo compared with occasional buyers (Table 3 ).

These results clearly indicate the need to increase the awareness of the EU organic food logo among consumers. Not only does the logo have low recognition, but also knowledge of the rules that EU organic food need to comply with are unknown to many consumers. The low consumer knowledge regarding organic food certification has previously been reported (Aertsens et al., 2009; Janssen and Hamm, 2012b) and may act as a barrier for organic food purchases (Vermeir and Ver-

Table 3. Recognition and objective knowledge of organic food logos

\begin{tabular}{|c|c|c|c|c|c|}
\hline Item & $\begin{array}{c}\text { Total } \\
\text { sample }\end{array}$ & \multicolumn{3}{|c|}{ Frequency of buying } & $P$-value \\
\hline \multicolumn{6}{|c|}{ Recognition of EU organic label } \\
\hline Yes & 31 & 22 & 39 & 49 & \multirow[t]{2}{*}{$<0.001^{1}$} \\
\hline No & 69 & 79 & 61 & 51 & \\
\hline \multicolumn{6}{|c|}{ Recognition of Belgian organic label } \\
\hline \multicolumn{6}{|c|}{ Objective knowledge (no. of correct answers to 4 statements) } \\
\hline 0 & 5.0 & 4.2 & 7.9 & 3.2 & \multirow[t]{5}{*}{$0.01^{1}$} \\
\hline 1 & 16.7 & 15.2 & 20.9 & 14.7 & \\
\hline 2 & 36.1 & 37.7 & 36.7 & 28.4 & \\
\hline 3 & 19.1 & 21.7 & 14.1 & 17.9 & \\
\hline 4 & 23.1 & 21.2 & 20.3 & 35.8 & \\
\hline Mean & 2.39 & $2.41^{\mathrm{ab}}$ & $2.18^{\mathrm{a}}$ & $2.68^{\mathrm{b}}$ & $0.002^{2}$ \\
\hline
\end{tabular}


beke, 2006). Janssen and Hamm (2012b) also reported consumer concerns with respect to the introduction of the EU logo in 2010. Consumers were afraid that the new logo would lead to downscaling of standards and trustworthiness of the inspection system. Janssen and Hamm (2012b) warned that sufficient communication would be needed about the meaning of this new EU logo during its introduction, and that this would be a major challenge during the introduction phase of the logo. Our results indicate that, in 2012, sufficient knowledge of EU organic logo does not exist, and that further communication campaigns are needed to increase the knowledge of the new EU logo, which may boost organic food purchases. As the voluntary organic certification logo Biogarantie carries higher awareness, it might be advisable to use both the mandatory EU logo and the Biogarantie logo during a transition period (Janssen and Hamm, 2012b). However, it is not clear how long a transition period will be required. It seems that even 2 years after the introduction on the EU logo awareness in Belgium is still much lower than for the Biogarantie logo, hence why the Biogarantie logo is still needed.

\section{Organic Food Involvement and General Attitudes Toward Organic Yogurt}

The 3 consumer groups also differ in terms of involvement with organic food. Habitual consumers have the highest involvement, followed by the occasional buyers and then nonbuyers (Table 4). This is consistent with Vermeir and Verbeke (2006), who reported high involvement to have a positive influence on organic food purchases. Increasing frequency of organic yogurt purchases also associates with more favorable general attitudes toward organic yogurt, similar to a report by Pieniak et al. (2010) for organic vegetable consumption (Table 4). As expected, purchase intention also increases with an increasing purchase frequency (Table 4).

\section{Importance of Yogurt Attributes}

The most important attributes of yogurt are taste, quality, and trustworthiness, followed by nutritional value, price, availability, and environmental friendliness (Table 4). Packaging, brand name, and using an organic logo are considered less important. Thus, having an organic logo is considered one of the least important attributes compared with the other yogurt attributes. This is consistent with other studies that indicated sensory quality or taste as an important attribute for organic food buyers (Magnusson et al., 2001; Torjusen et al., 2001; Kihlberg et al., 2005; Van Loo et al., 2010).

The importance of the different yogurt attributes, except for the brand name, depends on the type of consumer (Table 4). With an increasing frequency of purchasing organic yogurt-going from nonbuyer, to

Table 4. Importance of yogurt attributes, beliefs about organic yogurt, concerns and other factors

\begin{tabular}{|c|c|c|c|c|c|}
\hline \multirow[b]{2}{*}{ Item } & \multirow[b]{2}{*}{$\begin{array}{c}\text { Total } \\
\text { sample }\end{array}$} & \multicolumn{3}{|c|}{ Frequency of buying } & \multirow[b]{2}{*}{$\begin{array}{l}P \text {-value } \\
\text { (F-test) }\end{array}$} \\
\hline & & Nonbuyers & $\begin{array}{c}\text { Occasional } \\
\text { buyers }\end{array}$ & $\begin{array}{c}\text { Habitual } \\
\text { buyers }\end{array}$ & \\
\hline Involvement & 4.07 & $3.30^{\mathrm{a}}$ & $4.61^{\mathrm{b}}$ & $5.78^{\mathrm{c}}$ & $<0.001$ \\
\hline General attitude & 4.95 & $4.36^{\mathrm{e}}$ & $5.38^{\mathrm{f}}$ & $6.27^{\mathrm{g}}$ & $<0.001$ \\
\hline Purchase intention & 2.96 & $1.76^{\mathrm{a}}$ & $3.69^{\mathrm{b}}$ & $5.90^{\mathrm{c}}$ & $<0.001$ \\
\hline \multicolumn{6}{|l|}{ Importance of yogurt attributes } \\
\hline Taste & 6.40 & $6.29^{\mathrm{a}}$ & $6.54^{\mathrm{b}}$ & $6.55^{\mathrm{b}}$ & 0.009 \\
\hline Quality & 6.17 & $6.02^{\mathrm{a}}$ & $6.23^{\mathrm{a}}$ & $6.55^{\mathrm{b}}$ & $<0.001$ \\
\hline Trustworthiness & 5.68 & $5.46^{\mathrm{a}}$ & $5.79^{\mathrm{b}}$ & $6.26^{\mathrm{c}}$ & $<0.001$ \\
\hline Nutritional value & 5.31 & $5.07^{\mathrm{a}}$ & $5.47^{\mathrm{b}}$ & $5.83^{\mathrm{c}}$ & $<0.001$ \\
\hline Price & 5.23 & $5.24^{\mathrm{ab}}$ & $5.43^{\mathrm{a}}$ & $4.89^{\mathrm{b}}$ & 0.009 \\
\hline Availability & 5.12 & $4.98^{\mathrm{e}}$ & $5.17^{\mathrm{ef}}$ & $5.51^{\mathrm{f}}$ & 0.002 \\
\hline Environmental friendliness & 4.69 & $4.10^{\mathrm{a}}$ & $5.06^{\mathrm{b}}$ & $6.03^{\mathrm{c}}$ & $<0.001$ \\
\hline Packaging & 3.71 & $3.43^{\mathrm{a}}$ & $3.83^{\mathrm{b}}$ & $4.45^{\mathrm{c}}$ & $<0.001$ \\
\hline Brand name & 3.69 & 3.64 & 3.68 & 3.86 & 0.505 \\
\hline Provided with an organic logo & 3.68 & $2.78^{\mathrm{a}}$ & $4.22^{\mathrm{b}}$ & $5.85^{\mathrm{c}}$ & $<0.001$ \\
\hline \multicolumn{6}{|c|}{ Beliefs: organic versus conventional yogurt } \\
\hline Healthiness & 5.11 & $4.73^{\mathrm{e}}$ & $5.30^{\mathrm{f}}$ & $6.08^{\mathrm{g}}$ & $<0.001$ \\
\hline Environmental friendliness & 4.95 & $4.71^{\mathrm{e}}$ & $5.05^{\mathrm{f}}$ & $5.60^{\mathrm{g}}$ & $<0.001$ \\
\hline Quality & 4.78 & $4.43^{\mathrm{a}}$ & $4.95^{\mathrm{b}}$ & $5.70^{\mathrm{c}}$ & $<0.001$ \\
\hline Safety & 4.54 & $4.38^{\mathrm{a}}$ & $4.56^{\mathrm{a}}$ & $5.05^{\mathrm{b}}$ & $<0.001$ \\
\hline Taste & 4.50 & $4.08^{\mathrm{a}}$ & $4.64^{\mathrm{b}}$ & $5.63^{\mathrm{c}}$ & $<0.001$ \\
\hline Trustworthiness & 4.49 & $4.20^{\mathrm{a}}$ & $4.61^{\mathrm{b}}$ & $5.28^{\mathrm{c}}$ & $<0.001$ \\
\hline Packaging & 4.06 & $3.88^{\mathrm{a}}$ & $4.11^{\mathrm{b}}$ & $4.58^{\mathrm{c}}$ & $<0.001$ \\
\hline Availability & 3.40 & $3.26^{\mathrm{e}}$ & $3.40^{\mathrm{e}}$ & $3.83^{\mathrm{f}}$ & $<0.001$ \\
\hline Price & 2.68 & $2.53^{\mathrm{a}}$ & $2.71^{\mathrm{a}}$ & $3.16^{\mathrm{b}}$ & $<0.001$ \\
\hline
\end{tabular}

\footnotetext{
a-c Indicate significantly different means using Dunnett T3 post hoc.

e Indicate significantly different means using Scheffé post hoc.
} 
occasional buyer, to habitual buyer - the importance of nutritional value, trustworthiness, environmental friendliness, packaging, and organic logo increases (all $P<0.001$ ). The habitual buyer gives more importance to availability and quality and less to price compared with the 2 other consumer groups.

\section{Beliefs About Differences Between Conventional and Organic Yogurt}

Consumers have a positive perception of the quality of organic food. They evaluate organic yogurt more highly than conventional yogurt on the aspects healthiness, environmental friendliness, quality, safety, taste, trustworthiness, and packaging (Table 4). Consumers rate the healthiness of organic yogurt as the attribute with the greatest difference from conventional yogurt. This is consistent with other studies indicating that health and food safety are key drivers for organic food purchases (Magnusson et al., 2003; Padel and Foster, 2005; Yiridoe et al., 2005; Hughner et al., 2007; Gracia and Magistris, 2008; Van Loo et al., 2010), or for organic yogurt purchases specifically (Howlett et al., 2002). The second largest perceived difference between conventional and organic yogurt is the perception that organic yogurt is more environmentally friendly, which has also been identified as one of the main drivers of organic food purchases (Yiridoe et al., 2005; Gracia and Magistris, 2008; Mondelaers et al., 2009).

Furthermore, the taste of organic yogurt is also perceived better than conventional yogurt. Previous studies on organic food showed similar results, that is, organic food products are perceived as having a superior taste compared with conventional food products (Grankvist and Biel, 2001, 2007; Lockie et al., 2004; Van Loo et al., 2010). Kihlberg et al. (2005) reported that providing information about organic production has a positive effect on the liking of bread by its perceived sensory properties. Similarly, Toschi et al. (2012) reported taste as an important factor for organic yogurt purchases, as organic yogurt manufacturers and retailers claim that their product has a superior taste. Toschi et al. (2012) compared the sensory properties of conventional and organic yogurt and the effect of information on liking (blind and labeled test). Their results indicate no difference in odor, taste, and texture between organic and conventional yogurt. Their study confirms the presence of the labeling effect: conventional yogurt scored significantly higher when (misleadingly) labeled as organic compared with a blind test condition (unlabeled), and scored significantly lower when labeled as conventional compared with the blind test.

The price and availability of organic yogurt are evaluated less favorably than conventional yogurt.
Other studies revealed similar results, reporting price and availability to be the key barrier for organic food purchases (Yiridoe et al., 2005; Hughner et al., 2007; Van Loo et al., 2010).

Comparing the beliefs among the 3 consumer groups reveals that the beliefs toward organic yogurt are more positive with an increasing frequency of organic yogurt purchases. The beliefs about organic yogurt become more positive going from nonbuyers, to occasional buyers, to habitual buyers (all $P<0.001$ ) - except for safety, availability, and price, where no significant differences exist among nonbuyers and occasional buyers (Table 4). Consumers buying organic yogurt more frequently have a stronger belief that organic yogurt is healthier, more environmentally friendly, safer, more trustworthy, tastier, and has better quality and packaging. Even consumers who are currently not purchasing organic yogurt believe that organic yogurt is superior compared with conventional yogurt: they rate it as healthier, better for the environment, better in quality and taste, safer, more trustworthy, and better packaged. Despite positive beliefs toward organic yogurt, barriers preventing consumers from purchasing it still exist (Grunert, 2011), such as high price and low perceived availability. Both nonbuyers and occasional buyers evaluate the price and availability of organic yogurt to be less favorable compared with habitual buyers (Table 4).

\section{WTP for Organic Yogurt}

Approximately $11 \%$ of the participants would choose conventional yogurt instead of organic yogurt independent of its price. The other $89 \%$ prefer organic yogurt and would, on average, be willing to pay $€ 0.33$ extra for a yogurt priced at $€ 1.50$. This reveals an average premium of $22 \%$ (Table 5), which is clearly lower than current premiums in the Belgium market, being $37 \%$ in 2011 on average (VLAM, 2012). Anstine (2007) reported that consumers are also willing to pay more for yogurt labeled organic, and Napolitano et al. (2008) found WTP values of 6.5 and $4.7 \%$ for plain and low fat yogurt, respectively, with higher animal welfare standards.

Differences among the different groups of buyers were seen $(P<0.001$; Table 5 and Figure 1$)$. A large group of those currently not purchasing organic yogurt indicated they would either choose conventional yogurt independent of the price of organic yogurt (17\% of nonorganic buyers) or choose organic yogurt only if no price premium is evident (35\% of nonorganic buyers; Figure 1). These percentages were a lot lower for the occasional and habitual buyers who are more likely to be willing to spend a higher premium for organic yogurt. When comparing average WTP among the 3 groups, the habitual buyer is willing to pay a premium (40\%), which 
VAN LOO ET AL.

Table 5. Willingness to pay a price premium for 3 different types of buyers $(\% ; \mathrm{n}=687)$

\begin{tabular}{lccccc}
\hline Item & $\begin{array}{c}\text { Total } \\
\text { sample }\end{array}$ & Non buyer & $\begin{array}{c}\text { Occasional } \\
\text { buyer }\end{array}$ & $\begin{array}{c}\text { Habitual } \\
\text { buyer }\end{array}$ & $\begin{array}{c}P \text {-value } \\
(F \text {-test })\end{array}$ \\
\hline Mean (\% extra) & 21.9 & $15.2^{\mathrm{a}}$ & $23.1^{\mathrm{b}}$ & $39.9^{\mathrm{c}}$ & $<0.001$ \\
SD (\% extra) & 22.4 & 19.1 & 19.7 & 25.0 & \\
SE (\% extra) & 0.9 & 1.0 & 1.4 & 2.3 & \\
\hline
\end{tabular}

${ }^{a-c}$ Indicate significantly different means using Dunnett T3 post hoc.

is nearly 2.5 times as higher than nonbuyers (price premium of $15 \%$ on average; Table 4 ). Occasional buyers reported an average premium of $23 \%$ (Table 5 ). This is consistent with previous studies reporting higher WTP values for frequent buyers of organic food (Van Loo et al., 2011; Janssen and Hamm, 2012a). The habitual yogurt buyer is willing to pay a premium (40\%) similar to the current price premium charged for organic yogurt on the Belgian market in 2011(37\%). The occasional buyer is willing to spend less than the current market price (22\% compared with $37 \%$ ); however, the small differences between the WTP and the current market price reveal market potential. If more organic yogurt becomes available and prices drop, more occasional buyers might purchase the yogurt and could become habitual buyers. Conversely, the nonbuyers are only willing to spend a premium of $15 \%$, meaning that the premium would need to decrease considerably before they would consider choosing organic yogurt.

\section{Association Between Consumer Attitude, Knowledge About Logos, and Consumption}

Structural equation modeling was performed to analyze whether knowledge about the organic food logo and consumer attitudes are associated with the frequency of organic yogurt consumption. The tested model performs very well in explaining the variance in the dependent variable (Figure 2). The $\chi^{2}$ for the model is 4.3 with 4 degrees of freedom. The root mean square error of approximation value is 0.011 ; the validity of fit index is 0.99 and the comparative fit index is 0.99 , indicating that the validity-of-fit indices are satisfactory. The $\mathrm{R}^{2}$ value for the model explaining organic yogurt consumption is 0.32 ; thus consumer attitudes and knowledge account for $32 \%$ of the variance in selfreported organic yogurt consumption.

Objective knowledge has a relatively weak relationship with attitude toward organic yogurt. The association between objective knowledge and organic yogurt consumption is fully mediated by attitude. A direct relationship between objective knowledge and organic yogurt consumption has been included in the model but failed to reach significance. Finally, the structural equation analysis supports that attitude toward organic yogurt has a direct positive and relatively strong relationship with organic yogurt consumption, which corroborates classical attitude-behavior theories, suggesting that attitude is a predictor of behavior (Armitage and Conner, 2001; Ajzen and Fishbein, 2005). Vermeir and Verbeke (2006) reported that, despite a strong relationship between attitude and behavior toward sustainable dairy products, attitudes may not match consistently with behavioral intentions and behavior, which explains part of the share of variance not accounted for by the model. Consumer knowledge and attitudes have already been proven to be associated with organic food consumption, particularly organic vegetable consumption (Pieniak et al., 2010).

In order for the new EU organic food logo to be a success, consumers need to recognize it and know its meaning; however, both recognition and knowledge are relatively low. The current study identifies a need to inform and educate consumers more about this new logo. After being introduced on the market in 2010, a higher recognition would be expected by 2012 than the $31 \%$ reported in this study. One of the objectives of the $\mathrm{EU}$ organic food program is to have a harmonized EU organic food logo with high recognition to increase consumer confidence and stimulate organic sales. However, our study indicates that more effective communication campaigns may be needed to achieve these goals. With much higher recognition of the private organic certification logo compared with the EU organic label, it is likely that retailers and manufacturers will continue to include the voluntary private organic certification logos on their product in combination with the EU organic logo until consumers have a better awareness and trust in the EU logo. If consumers become more aware of the EU organic logo, the voluntary organic food logos will not need to be included in addition to the mandatory EU organic logo. This would free up space on the front of the package, which is important, from a marketing point of view, for manufacturers and retailers. Furthermore, eliminating optional logos can reduce (transaction) costs because the need to be compliant to an additional organic certification scheme will no longer exist. Most importantly, one less label will lower the risk of possible information overload and ignorance among consumers; as such, consistent use of one label 


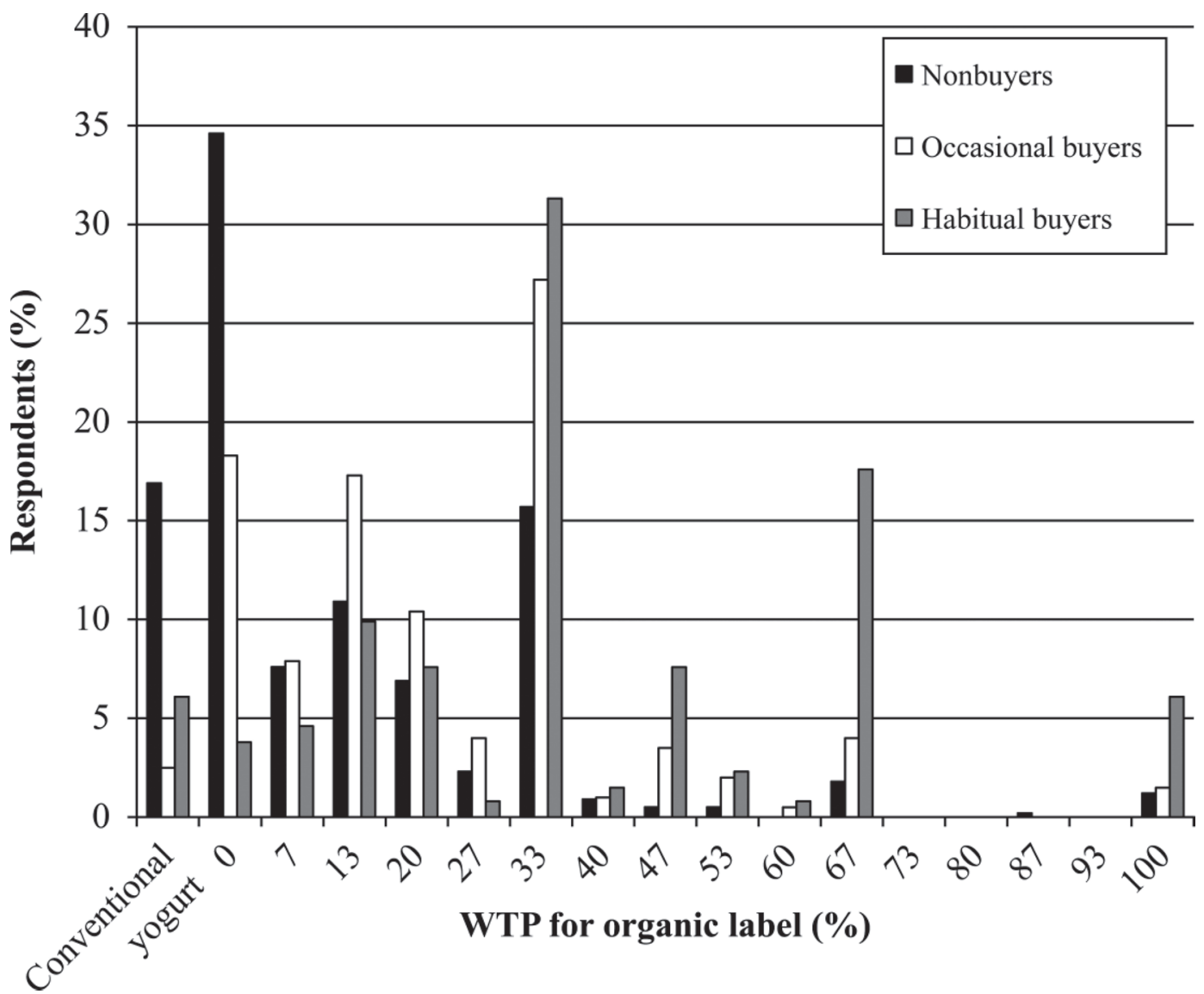

Figure 1. The percentage premium that 3 types of buyers would be willing to pay (WTP) for organic yogurt.

only may reduce uncertainty, increase trust, and facilitate consumer choice (Verbeke, 2005).

Our results can contribute to improving the effectiveness of current marketing strategies of organic yogurt to both existing and potential consumers. Our study indicates that the organic yogurt consumption is not strongly influenced by socio-demographics, as only sex is found to have a significant effect. Consumers believe that organic yogurt is better in many aspects compared with conventional yogurt, which provides a strong potential to capitalize on. These positive beliefs about organic yogurt are stronger for consumers who purchase organic yogurt compared with those who do not. Consumers purchasing organic yogurt have a stronger perception that organic yogurt is healthier, more environmentally friendly, more trustworthy, tastier, and has a better quality than those who do not purchase organic yogurt. Food marketers are advised to reinforce the positive image of organic yogurt in their aim to increase consumption.

Furthermore, consumers are willing to pay a premium for organic yogurt, but too high of prices are barri-

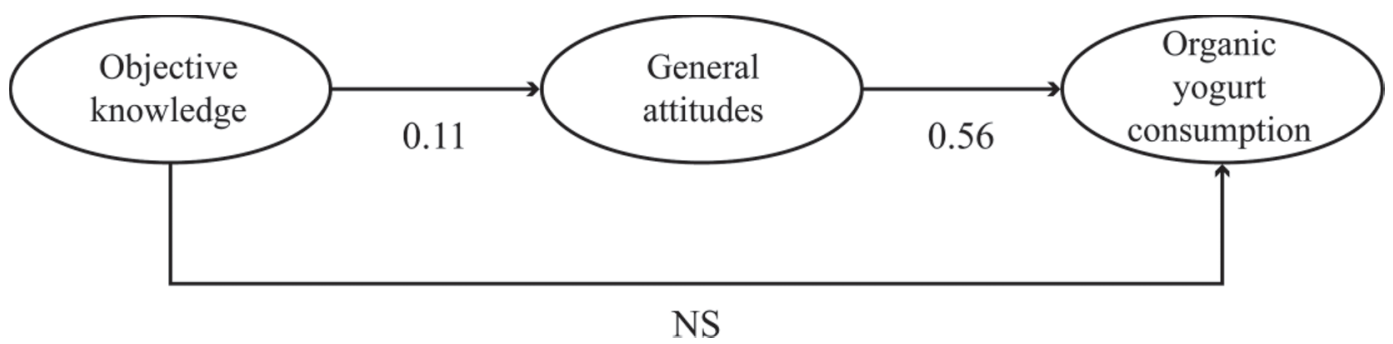

Figure 2. The structural equations model (standardized solution) reveals the positive association between knowledge, attitudes, and the frequency of purchasing and consuming organic yogurt. Coefficients are significant at $P<0.001$ (NS = insignificant paths). 
ers for organic yogurt purchases, especially among the current nonusers. The WTP for organic yogurt ranged from $15 \%$ for nonbuyers to $23 \%$ for occasional buyers and $40 \%$ for habitual buyers, indicating the market potential for this product. The WTP for organic yogurt for the occasional buyers is currently less than the current market price; however, this suggests that a drop in market price can result in occasional buyers becoming habitual buyers.

\section{Limitations}

This study faces a few limitations; the first limitation of our study pertains to its narrow geographic scope and sample bias toward younger and more highly educated consumers. As a result, the findings of this study should be interpreted within the specific frame of its sample, and generalizations to the broader public remain to be further validated. Another limitation is the hypothetical nature of the WTP estimates. More research using nonhypothetical and incentive-aligned methods are desirable, such as experimental auctions or nonhypothetical choice experiments to validate our findings in relation to WTP. Second, our study assessed the importance of brand name as an attribute for yogurt in general, but it did not account for the possible effect of brand names on organic versus conventional yogurt products. This area of study deserves more attention in future research, as an increasing amount of retailers are expanding their private label (store brand) product assortment and sometimes even incorporate an organic alternative into these store brand product categories. Very few organic food studies have investigated the implications of this trend thus far (Perrini et al., 2010). An important issue, in this respect, is whether and to what extent brands in general and private labels in particular can reinforce the consumer appeal and value of organic products.

Future studies could test the effect of other variables, such as subjective or perceived knowledge on organic yogurt consumption. It is expected that the new EU organic food logo will gain awareness in future, so future studies can evaluate the evolution of awareness over time and its effect on consumer behavior.

\section{CONCLUSIONS}

The current study identifies a need to inform and educate consumers more about the new EU organic food logo to achieve high recognition and, thus, increase consumer confidence and stimulate organic sales. This could contribute to the effectiveness of current marketing strategies of organic yogurt. As objective knowledge is indirectly positively linked to organic yogurt consumption through consumer attitudes, this study confirms the importance of improving the consumer knowledge about organic food certification. Thus, educating consumers about the organic logo and its meaning is essential. However, objective knowledge does not have a direct effect, suggesting that education alone will not suffice. Additionally, marketing strategies should reinforce positive attitudes toward organic yogurt. Based on our findings, positive attitudes toward organic yogurt would result in increased organic yogurt consumption. This information is relevant for both food marketers as well as food and health policy makers, who are recommended to educate consumers about organic food and reinforce positive attitudes toward organic yogurt.

\section{REFERENCES}

Aertsens, J., K. Mondelaers, W. Verbeke, J. Buysse, and G. van Huylenbroeck. 2011. The influence of subjective and objective knowledge on attitude, motivations and consumptions of organic food. Br. Food J. 113:1353-1378.

Aertsens, J., W. Verbeke, K. Mondelaers, and G. van Huylenbroeck. 2009. Personal determinants of organic food consumption: A review. Br. Food J. 111:1140-1167.

Ajzen, I., and M. Fishbein. 2005. The influence of attitudes on behavior. Pages 173-221 in The Handbook of Attitudes. Albarracín, D., B. T. Johnson, and M. P. Zanna, ed. Erlbaum, Mahwah, NJ.

Anstine, J. 2007. Organic and all natural: Do consumers know the difference. J. Appl. Econ. Policy 26:15-28.

Armitage, C. J., and M. Conner. 2001. Efficacy of the theory of planned behaviour: A meta-analytic review. Br. J. Soc. Psychol. 40:471-499.

Batte, M. T., N. H. Hooker, T. C. Haab, and J. Beaverson. 2007. Putting their money where their mouths are: Consumer willingness to pay for multi-ingredient, processed organic food products. Food Policy 32:145-159.

Bell, R., and D. W. Marshall. 2003. The construct of food involvement in behavioral research: scale development and validation. Appetite 40:235-244.

Bellows, A. C., B. Onyango, A. Diamond, and W. K. Hallman. 2008. Understanding consumer interest in organics: Production values vs. purchasing behavior. J. Agric. Food Ind. Organ. 6:1-2.

BioForum. 2011. Beknopt marktoverzicht voor biologische zuivel in Vlaanderen en Europa. Accessed Sep. 12, 2012. http://bioforum. bioadmin.be/sites/default/files/MS\%20biozuivel\%20201110.pdf.

BioForum. 2012. Waarom Biogarantie. Méér dan bio. Accessed Sep. 12, 2012. http://www.bioforumvlaanderen.be/biosector/ basisinformatie/producenten/waarombiogarantie.

Bollen, K. A. 1989. Structural Equations with Latent Variables. Wiley, New York, NY.

Browne, M., and R. Cudeck. 1993. Alternative ways of assessing model fit. 136-162 in Testing Structural Equation Models. K. Bollen, and J. Long, ed. Sage, Newbury Park, CA.

de Magistris, T., and A. Gracia. 2008. The decision to buy organic food products in Southern Italy. Br. Food J. 110:929-947.

European Commission. 2012. Special Eurobarometer 389: European attitudes towards food security, food quality and the countryside. Accessed Sep. 12, 2012. http://ec.europa.eu/public_opinion/ archives/ebs/ebs_389_en.pdf.

Gracia, A., and T. Magistris. 2008. The demand of organic foods in the south of Italy: A discrete choice model. Food Policy 33:386-396.

Grankvist, G., and A. Biel. 2001. The importance of beliefs and purchase criteria in the choice of eco-labeled food products. J. Environ. Psychol. 21:406-409.

Grankvist, G., and A. Biel. 2007. Predictors of purchase of eco-labelled food products: A panel study. Food Qual. Prefer. 18:701-708. 
Grunert, K. G. 2011. Sustainability in the food sector: A consumer behaviour perspective. Int. J. Food Syst. Dynamics 2:207-218.

Hoefkens, C., W. Verbeke, J. Aertsens, K. Mondelaers, and J. Van Camp. 2009. The nutritional and toxicological value of organic vegetables: Consumer perception versus scientific evidence. Br. Food J. 111:1062-1077.

Hoek, A. C., P. A. Luning, P. Weijzen, W. Engels, F. J. Kok, and C. de Graaf. 2011. Replacement of meat by meat substitutes. A survey on person- and product-related factors in consumer acceptance. Appetite 56:662-673.

Honkanen, P., B. Verplanken, and S. O. Olsen. 2006. Ethical values and motives driving organic food choice. J. Consum. Behav. 5:420-430.

Hoogland, C. T., J. de Boer, and J. J. Boersema. 2007. Food and sustainability: Do consumers recognize, understand and value onpackage information on production standards? Appetite 49:47-57.

Howlett, B., M. McCarthy, and S. O'Reilly. 2002. An examination of consumers' perceptions on organic yogurt. Pages 3-27 in Agribusiness Discussion Paper No. 38. Department of Business and Development, National University of Ireland, Cork.

Hughner, R. S., P. McDonagh, A. Prothero, C. J. Shultz II, and J. Stanton. 2007. Who are organic food consumers? A compilation and review of why people purchase organic food. J. Consum. Behav. 6:94-110

IFOAM/FiBL. 2012. The World of Organic Agriculture-Statistics and Emerging Trends 2012. H. Willer and L. Kilcher, ed. Research Institute of Organic Agriculture (FiBL), Frick, Switzerland; International Federation of Organic Agriculture Movements (IFOAM), Bonn, Germany.

Janssen, M., and U. Hamm. 2012a. Product labeling in the market for organic food: Consumer preferences and willingness-to-pay for different organic certification logos. Food Qual. Prefer. 25:9-22.

Janssen, M., and U. Hamm. 2012b. The mandatory EU logo for organic food: Consumer perceptions. Br. Food J. 114:335-352.

Kihlberg, I., L. Johansson, Ø. Langsrud, and E. Risvik. 2005. Effects of information on liking of bread. Food Qual. Prefer. 16:25-35.

Krystallis, A., C. Fotopoulos, and Y. Zotos. 2006. Organic consumers' profile and their willingness to pay (WTP) for selected organic food products in Greece. J. Int. Consum. Mark. 19:81-107.

Lockie, S., K. Lyons, G. Lawrence, and J. Grice. 2004. Choosing organics: A path analysis of factors underlying the selection of organic food among Australian consumers. Appetite 43:135-146.

Lusk, J. L. 2011. External validity of the food values scale. Food Qual. Prefer. 22:452-462.

Magnusson, M. K., A. Arvola, U. K. Hursti, L. Aberg, and P. Sjoden. 2001. Attitudes towards organic foods among Swedish consumers. Br. Food J. 103:209-227.

Magnusson, M. K., A. Arvola, U. K. Hursti, L. Åberg, and P. Sjödén. 2003. Choice of organic foods is related to perceived consequences for human health and to environmentally friendly behaviour. Appetite 40:109-117.

Mintel. 2011. Natural and Organic Food and Beverage: The Consumer, US - November 2011. Mintel database. http://store.mintel. $\mathrm{com} /$ natural-and-organic-food-and-beverage-the-consumer-usnovember-2011.

Mondelaers, K., W. Verbeke, and G. Van Huylenbroeck. 2009. Importance of health and environment as quality traits in the buying decision of organic products. Br. Food J. 111:1120-1139.

Napolitano, F., C. Pacelli, A. Girolami, and A. Braghieri. 2008. Effect of information about animal welfare on consumer willingness to pay for yogurt. J. Dairy Sci. 91:910-917.

O'Donovan, P., and M. McCarthy. 2002. Irish consumer preference for organic meat. Br. Food J. 104:353-370.

Olsen, S. O., J. Scholderer, K. Brunsø, and W. Verbeke. 2007. Exploring the relationship between convenience and fish consumption: A cross-cultural study. Appetite 49:84-91.

Padel, S., and C. Foster. 2005. Exploring the gap between attitudes and behaviour. Br. Food J. 107:606-625.

Pearson, D., J. Henryks, and H. Jone. 2011. Organic food: What we know (and do not know) about consumers. Renew. Agric. Food Syst. 26:171-177.
Pérez-Cueto, F. J. A., Z. Pieniak, and W. Verbeke. 2011. Attitudinal determinants of fish consumption in Spain and Poland. Nutr. Hosp. 26:1412-1419.

Perrini, F., S. Castaldo, N. Misani, and A. Tencati. 2010. The impact of corporate social responsibility associations on trust in organic products marketed by mainstream retailers: A study of Italian consumers. Bus. Strategy Environ. 19:512-526.

Pieniak, Z., J. Aertsens, and W. Verbeke. 2010. Subjective and objective knowledge as determinants of organic vegetable consumption. Food Qual. Prefer. 21:581-588.

Pieniak, Z.. W. Verbeke, J. Scholderer, K. Brunsø, and S. O. Olsen. 2008. Impact of consumers' health beliefs, health involvement and risk perception on fish consumption: A study in five European countries. Br. Food J. 110:898-915.

Pino, G., A. M. Peluso, and G. Guido. 2012. Determinants of regular and occasional consumers' intentions to buy organic food. J. Consum. Aff. 46:157-169

Soil Association. 2012. Organic Market Report 2012. Accessed Sep. 12, 2012. http://www.soilassociation.org/marketreport.

Stayman. D. M., and R. Batra. 1991. Encoding and retrieval of ad affect in memory. J. Mark. Res. 28:232-239.

Torjusen, H., G. Lieblein, M. Wandel, and C. A. Francis. 2001. Food system orientation and quality perception among consumers and producers of organic food in Hedmark County, Norway. Food Qual. Prefer. 12:207-216.

Toschi, T. G., A. Bendini, S. Barbieri, E. Valli, M. L. Cezanne, K. Buchecker, and M. Canavari. 2012. Organic and conventional nonflavoured yogurts from the Italian market: Study on sensory profiles and consumer acceptability. J. Sci. Food Agric. 92:2788-2795.

Tsakiridou, E., C. Boutsouki, Y. Zotos, and K. Mattas. 2008. Attitudes and behaviour towards organic products: An exploratory study. Int. J. Retail Distrib. Manag. 36:158-175.

Turco, G. 2002. Organic food-An opportunity at who's expense? Industry Note, Food and Agribusiness Research. Rabobank International, Sydney, Australia.

Van Loo, E. J., V. Caputo, R. M. Nayga, and M. Canavari, and S. C. Ricke. 2012. Organic meat marketing. Pages 67-85 in Organic Meat Production and Processing. S. C. Ricke, E. J. Van Loo, M. G. Johnson, and C. A. O'Bryan, ed. Wiley-Blackwell, Oxford, UK.

Van Loo, E., V. Caputo, R. M. Nayga, J. Meullenet, P. G. Crandall, and S. C. Ricke. 2010. Effect of organic poultry purchase frequency on consumer attitudes toward organic poultry meat. J. Food Sci. 75:S384-S397.

Van Loo, E. J., V. Caputo, R. M. Nayga Jr., J. Meullenet, and S. C. Ricke. 2011. Consumers' willingness to pay for organic chicken breast: Evidence from choice experiment. Food Qual. Prefer. 22:603-613.

Vanhonacker, F., and W. Verbeke. 2009. Buying higher welfare poultry products? Profiling Flemish consumers who do and do not. Poult. Sci. 88:2702-2711.

Verbeke, W. 2005. Agriculture and the food industry in the information age. Eur. Rev. Agric. Econ. 32:347-368.

Vermeir, I., and W. Verbeke. 2006. Sustainable food consumption: Exploring the consumer "attitude and behavioral intention" gap. J. Agric. Environ. Ethics 19:169-194.

VLAM (Vlaams Centrum voor Agro- en Visserijmarketing vzw). 2012. Lichte groei van de biobestedingen in 2011 (Small growth of organic spending in 2011). GfK Panel data $2011 \mathrm{AB}$, version April 2012. Accessed July 10, 2012. http://www.vlam.be/marketinformationdocument/files/thuisverbruikbio2011.pdf.

Yiridoe, E. K., S. Bonti-Ankomah, and R. C. Martin. 2005. Comparison of consumer perceptions and preference toward organic versus conventionally produced foods: A review and update of the literature. Renew. Agric. Food Syst. 20:193-205.

Zaichkowsky, J. L. 1985. Measuring the involvement construct. J. Consum. Res. 12:341-352.

Zander, K., and U. Hamm. 2010. Consumer preferences for additional ethical attributes of organic food. Food Qual. Prefer. 21:495-503. 